\title{
A SHARP DOUBLE INEQUALITY INVOLVING TRIGONOMETRIC FUNCTIONS AND ITS APPLICATIONS
}

\author{
ZHEN-HANG YANG AND Yu-Ming CHU
}

Abstract. We present the best possible parameters $p, q \in(0,1]$ such that the double inequality $\frac{1}{3 p^{2}} \cos (p x)+1-\frac{1}{3 p^{2}}<\frac{\sin (x)}{x}<\frac{1}{3 q^{2}} \cos (q x)+1-\frac{1}{3 q^{2}}$ holds for all $x \in(0, \pi / 2)$. As applications, some new inequalities for the sine integral, Catalan constant and Schwab-Borchardt mean are found.

Mathematics subject classification (2010): 26D05, 26E60. Borchardt.

Keywords and phrases: Jordan inequality, cosine function, sine integral, Catalan constant, Schwab-

\section{REFERENCES}

[1] K. S. K. Iyengar, B. S. Madhava Rao And T. S. Nanjundiah, Some trigonometrical inequalities, Half-Yearly J. Mysore Univ. Sect. B., N. S., 1945, 6: 1-12.

[2] F. QI, L.-H. CUI AND S.-L. XU, Some inequalities constructed by Tchebysheff's integral inequality, Math. Inequal. Appl., 1999, 2 (4): 517-528.

[3] E. NEUMAN AND J. SÁNDOR, On some inequalities involving trigonometric and hyperbolic functions with emphasis on the Cusa-Huygens, Wilker, and Huygens inequalities, Math. Inequal. Appl., 2010, 13 (4): 715-723.

[4] Y. Lv, G. Wang, Y. CHU, A note on Jordan type inequalities for hyperbolic functions, Appl. Math. Lett., 2012, 25 (3): 505-508.

[5] R. KlÉn, M. Visuri And M. VuORInen, On Jordan type inequalities for hyperbolic functions, J. Inequal. Appl., 2010, Article ID 362548, 14 pages.

[6] Z.-H. YANG, New sharp Jordan type inequalities and their applications, Gulf. J. Math., 2014,2 (1): $1-10$.

[7] L. ZHU, A source of inequalities for circular functions, Comput. Math. Appl., 2009, 58 (10): 19982004.

[8] Z.-H. YANG, Sharp bounds for Seiffert mean in terms of weighted power means of arithmetic mean and geometric mean, Math. Inequal. Appl., 2014, 17 (2): 499-514.

[9] Z.-H. YANG, Y.-M. CHU, Y.-Q. Song AND Y.-M. LI, A Sharp double inequality for trigonometric functions and its applications, Abstr. Appl. Anal., 2014, Article ID 592085, 9 pages.

[10] S.-H. WU AND L. DEBNATH, A new generalized and sharp version of Jordan's inequality and its applications to the improvement of the Yang Le inequality, Appl. Math. Lett., 2006, 19 (12): 13781384.

[11] S.-H. Wu, Sharpness and generalization of Jordan's inequality and its applications, Taiwanese J. Math., 2008, 12 (2): 325-336.

[12] Z.-H. YANG, Refinements of a two-sided inequality for trigonometric functions, J. Math. Inequal., 2013, 7 (4): 601-615.

[13] Z.-H. YAng AND Y.-M. Chu, A note on Jordan, Adamović-Mitrinović, and Cusa inequalities, Abstr. Appl. Anal., 2014, Article ID 364076, 12 pages.

[14] D. M. BRADLEY, A class of series acceleration formulae for Catalan's constant, Ramanujan J., 1999, 3 (2): 159-173. 
[15] D. Borwein, J. M. Borwein, M. L. Glasser and J. G. Wan, Moments of Ramanujan's generalized elliptic integrals and extensions of Catalan's constant, J. Math. Anal. Appl., 2011, 384 (2): 478-496.

[16] D. H. Bailey, J. M. Borwein, A. Mattingly and G. Wightwick, The computation of previously inaccessible digits of $\pi^{2}$ and Catalan's constant, Notices Amer. Math. Soc., 2013, 60 (7): 844-854.

[17] Z.-H. YAng, Y.-M. ChU AND X.-J. TAO, A double inequality for the Trigamma function and it applications, Abstr. Appl. Anal., 2014, Article ID 702718, 9 pages.

[18] E. Neuman And J. SÁndor, On the Schwab-Borchardt mean, Math. Pannon, 2003, 14 (2): $253-$ 266.

[19] E. Neuman And J. SÁndor, On the Schwab-Borchardt mean II, Math. Pannon, 2006, 17 (1): 49-59.

[20] E. Neuman, Inequalities for the Schwab-Borchardt mean and their applications, J. Math. Inequal., 2011, 5 (4): 601-609. 